Acta Hispanica (2020) Supplementum II: 759-769

\title{
MONTAIGNE Y EL ENSAYO DEL NUEVO MUNDO
}

\section{LILIANA WEINBERG MARCHEVSKY}

\author{
Centro de Investigaciones sobre América Latina y el Caribe, UNAM
}

\begin{abstract}
Resumen: Se estudia la estrecha relación entre ensayo y Nuevo Mundo. La preocupación por América está ya presente en la obra de Montaigne, y a la vez el ensayo se hace presente cada vez con mayor fuerza en el mundo americano. La propia figura de Montaigne fue objeto de admiración y reflexión por parte de muchos de los principales ensayistas en esta región. Se revisan algunas de las consideraciones de varios de los mayores representantes del pensamiento y el ensayo latinoamericano en torno a Montaigne para mostrar que, a pesar de que han sido frecuentemente desatendidos por la crítica especializada, constituyen aportes sustantivos a los estudios montaigneanos.
\end{abstract}

Palabras clave: América Latina, Nuevo Mundo, Montaigne, ensayo.

\begin{abstract}
This article examines the close relationship between the essay and the New World. The concern about the American continent is already present in Montaigne's work, while essays gain more and more presence in the American world, and Montaigne's figure itself was an object of admiration and reflection to many of the major essayists in the region. This article goes through some considerations made by several of the main intellectual representatives of the Latin American essay about Montaigne in order to demonstrate that even though these authors have often been neglected by specialized criticism, their contributions to Montaignean studies are substantial.
\end{abstract}

Keywords: Latin America, New World, Montaigne, Essay.

"Nuestro mundo acaba de encontrar otro." Michel de Montaigne, Ensayos, III, VI.

Existe una estrecha relación entre el nuevo mundo del ensayo y el ensayo del nuevo mundo. Es innegable la importancia que ha tenido y sigue teniendo la producción ensayística en América Latina: nuestros más grandes escritores e intelectuales se fueron apropiando de un género al que dotaron de nuevos alcances reflexivos, éticos y estéticos, con el objeto de hacer inteligible su mundo. Y tanto quienes escribieron ensayo de corte personal y autobiográfico como quienes se dedicaron al ensayo de corte ideológico, histórico y de crítica cultural, tanto aquellos que se preocuparon por profundizar en la forma ensayo en sí misma como aquellos que buscaron entretejerla con la narrativa y la lírica, se dedicaron también a reflexionar en torno a la figura del primer ensayista e hicieron aportes sustantivos a la comprensión de su obra.

Si bien se ha estudiado con mayor detalle la influencia que tuvo la incorporación de las noticias del descubrimiento de América en la obra de Montaigne, poco se ha 
reconocido el aporte que los escritores de este Nuevo Mundo hicieron al estudio de la obra y las ideas del autor de los Ensayos.

Es notable cómo particularmente desde fines del siglo XIX proliferan las referencias a la obra del gran autor francés. La nómina de las figuras que dedicaron importantes reflexiones a Montaigne es muy amplia, desde los trabajos pioneros de Juan Montalvo o Ricardo Sáenz Hayes hasta los textos de Pedro Henríquez Ureña, Alfonso Reyes, Ezequiel Martínez Estrada, José Lezama Lima, Martín Cerda, o los más recientes de autores vivos como el mexicano Adolfo Castañón, el colombiano Pablo Montoya o el chileno Pablo Oyarzún, amén de las recreaciones literarias de Jorge Luis Borges, Juan José Arreola, Jorge Edwards o Antonio José Ponte, en la línea de Vila-Matas. Y desde luego que muchos de nuestros grandes ensayistas y estudiosos del ensayo, a la hora de reflexionar sobre el género, parten indefectiblemente de Montaigne, como es el caso de José Luis Martínez (1958).

En este trabajo propongo asomarnos a ese momento dorado de la reflexión sobre Montaigne que se dio en nuestra América a mediados del siglo XX, y esto en líneas tales como su visión del Nuevo Mundo; sus aportes a la fundación de un nuevo género, un estilo, una escritura; sus contribuciones a la renovación del pensamiento; su particular concepción del sujeto y la figuración del yo, entre otras.

Contamos con reflexiones de tan alto valor como las que le dedica Pedro Henríquez Ureña en Las corrientes literarias al referirse al tema americano, como lo hará años más tarde Germán Arciniegas, en "Nuestra América es un ensayo". Otro de nuestros ensayistas capitales, Alfonso Reyes, quien frecuentó a Montaigne y se refirió a él en múltiples oportunidades, desde el tema americano y la utopía en Última Tule, hasta su carácter de pensador el escritor. En 1921 publica "Montaigne y la mujer", y Montaigne está en la base de su definición del ensayo como "ese centauro de los géneros", en diálogo con Huxley. Valiosas son también las reflexiones sobre el pensamiento de Montaigne en el caso de escritores como Ezequiel Martínez Estrada, quien lo recupera como "filósofo impremeditado", sin olvidar a Jorge Luis Borges y Juan José Arreola, precedentes de la recreación literaria de la figura de Montaigne que en años recientes nos darán Jorge Edwards y Antonio José Ponte. Con solo asomarnos a sus reflexiones confirmamos que la exclusión de los grandes autores hispanoamericanos de la familia montaigneana es una injusticia que debemos saldar.

\section{El ensayo del Nuevo Mundo}

Mucho debe esta nueva clase de textos a las repercusiones que tuvo el descubrimiento del mundo americano para la mentalidad europea. Las novedades americanas se cuelan en la obra de Montaigne, quien responde con curiosidad y con indignación a los avances de la conquista de América. Llegan a Montaigne las primeras noticias del Nuevo Mundo, grabados, objetos que colecciona. Montaigne ha logrado incluso hablar, a través de un intérprete, con un indígena que llegó para ser exhibido como rareza en un desfile ante el rey. 
Progresivamente, y tras un primer momento de "tupinambización" de su mirada, Montaigne escribe "De los caníbales", donde reflexiona sobre el tema a partir de las noticias que llegan de los primeros franceses que arribaron a las costas del Brasil. Más tarde Montaigne dará cuenta de las noticias que llegan sobre el descubrimiento de los mundos azteca e inca, tal como consta en "De los coches". Vincula las noticias de América con sus propias reflexiones sobre el tema de la verdad, la cercanía con la naturaleza. Incluso el tema americano aparece desde el aviso al lector: "que si yo hubiere estado en esas naciones de las que se dice viven todavía en la dulce libertad de las primeras leyes de la naturaleza, te aseguro que gustosamente me habría pintado por entero, y desnudo" (Montaigne, 1998: 39).

Eximios ensayistas como Pedro Henríquez Ureña y Alfonso Reyes fueron ampliamente conscientes de la importancia y el eco que tuvieron las reflexiones de Montaigne sobre la realidad americana para el reconocimiento de la especificidad de nuestro continente y de su "mayoría de edad". Así lo muestran las páginas donde Pedro Henríquez Ureña se refiere a la discusión en torno al tema de los indígenas en distintos lugares de Europa. Con su consabida lucidez anota:

La discusión alcanza su mayor altura con Montaigne, en dos ensayos famosos - uno sobre los caníbales, el otro sobre los carruajes- y en muchas observaciones dispersas. Montaigne llevó la crítica de la civilización europea, en comparación con el estado salvaje, a sus consecuencias extremas. Había leído unas cuantas crónicas de viajes y conquistas; además, había conversado con viajeros, marineros, mercaderes, y aun con salvajes brasileños llevados a Rouen durante el reinado de Carlos IX (1949: 28).

Añade Henríquez Ureña que "La defensa del salvaje [...] beneficia no sólo a las tribus pacíficas, como los taínos que encontró Colón en las Antillas; incluye atrevidamente también a los caníbales" (1949: 29). Descubre acertadamente que "condena, con el mismo espíritu de Las Casas, la invasión europea [...] y comprende -como muy pocos europeos en su tiempo- que había grandes civilizaciones en América cuando llegaron los españoles" (1949: 30). Con Montaigne, dice Henríquez Ureña, se inicia una tradición reflexiva en torno al indígena que dio "nuevo sustento al ávido pensamiento filosófico" (1949: 31).

A estas reflexiones pueden añadirse las de Alfonso Reyes, quien hacia los años de la segunda guerra mundial, y aun antes, se preocupa por el tema americano y la utopía de América, recuperando la maravilla del descubrimiento, el pensamiento humanista y ese "exotismo americano" cargado de una intención política y moral. Según él América se vincula con una imagen a priori: "la Edad de Oro de los antiguos, el estado de inocencia natural"; Reyes ve en Montaigne uno de "los más nobles maestros del pensamiento europeo" que pide "al Nuevo Mundo un estímulo para el perfeccionamiento político de los pueblos": 
Montaigne y el ensayo del Nuevo Mundo

El testimonio de Montaigne es singularmente expresivo. En su alma se da el drama del Descubrimiento envuelto en aquella clara música de ideas que todavía nos conmueve. Montaigne reconoce que el solo contraste entre el Antiguo y el Nuevo Mundo lo despertó a esa comprensión para todas las doctrinas que Bacon y Shakespeare aprenderán de él [...] Durante la juventud de Montaigne, América se iba ensanchando día por día, y la creciente gravitación de América parece irlo levantando sobre el nivel moral de su tiempo. Leía con avidez los relatos de los cronistas de Indias; y además, como funcionario de Burdeos, veía llegar y admiraba los efectos y productos de la nueva zona generosa. [...] Montaigne se interesa, traduce poemas y canciones de los caníbales. Dispuesto siempre a abrir la ventana de la paradoja, se le antoja preguntarse si, después de todo, la civilización acostumbrada no sería un inmenso desvío; si el hombre de América [...] no estaría más cerca del Creador; si las costumbres no tendrían tan sólo un fundamento relativo $[\ldots]$ América tortura a sus prisioneros de guerra; pero Europa, piensa Montaigne, se permite mayores torturas en nombre de la religión y de la justicia. Y ved aquí brotar, en la mente de un europeo representativo, los preanuncios de los más avanzados y aun los más audaces puntos de vista que ofrece el espíritu moderno (Reyes, 1960: 58-59).

Si bien se ha estudiado con mayor detalle la influencia que tuvo en la obra de Montaigne la progresiva incorporación de las noticias del descubrimiento de América, poco es lo que se ha reconocido todavía en cuanto al significado que tuvo la reflexión sobre América para la propia consolidación del género: se trata en este sentido de un nuevo mundo del ensayo. En efecto, no solo el descubrimiento de América y de las distintas culturas de la región, y en general el tema americano, se hacen presentes en los Ensayos, sino que además surgen reflexiones en torno a conquista y colonización, noticias sobre pueblos con otras costumbres, reflexión en torno a la bondad e ingenuidad de los nuevos pueblos, su relación con las leyes, etc., así como también la apertura de horizontes, el relativismo cultural, la idea de naturaleza, tuvieron incidencia en la constitución del género. Un lugar especial ocupa la influencia de la obra del padre Las Casas en el propio Montaigne. La toma de distancia crítica respecto de la propia cultura que adopta el padre Las Casas es un gesto fundacional que comparte Montaigne. La obra de Las Casas - como lo adelanta Henríquez Ureña- tuvo el valor de una fuente fundamental para la crítica de la colonización en el ensayo "De los coches".

En cuanto al ensayo del nuevo mundo, es innegable la importancia que ha tenido y sigue teniendo la producción ensayística en América Latina. Nuestros intelectuales lograron inscribir en el ensayo un estilo del pensar y el traducir la vida americana. Tal como lo expresó Germán Arciniegas, nuestra América es un ensayo: “América surge en el mundo, con su geografía y sus hombres, como un problema. Es una novedad insospechada que 
rompe con las ideas tradicionales. América es ya, en sí, un problema, un ensayo del nuevo mundo, algo que tienta, provoca, desafía a la inteligencia" (1979: 5).

Sin embargo poco es lo que se conoce del aporte que a través de los siglos los escritores de ese Nuevo Mundo hicieron al estudio del género, así como de la obra y las ideas del autor de los Essais. Así, por ejemplo, en el portentoso Dictionnaire de Michel de Montaigne editado por Philippe Desan no aparece mencionado sino de manera tangencial un solo estudioso latinoamericano: el chileno-costarricense Juan Durán Luzio (precisamente quien confirmó la lectura de Las Casas hecha por Montaigne).

\section{E1 nuevo mundo del ensayo}

¿En qué consiste, por lo demás, ese nuevo mundo del ensayo? En un cambio fundamental en la relación entre el autor, la obra, el lector, la tradición, las lecturas, el lenguaje, el conocimiento, la vida. Un ejercicio de reflexión, un ejercicio de lucidez, que un autor entabla a partir de la observación de la propia experiencia y las propias lecturas, que organiza a través de la escritura del mundo y comparte con sus lectores, guiado por la fidelidad a la verdad, la autenticidad y la responsabilidad por sus palabras.

La lista de autores latinoamericanos que han comentado la obra de Montaigne en el siglo XIX es muy amplia, y podemos comenzar con la lectura de Francisco de Miranda, de quien consta que tuvo acceso a L'Esprit de Montaigne, “esto es, una condensación de los Ensayos" (Archivo del General Miranda citado por Sáenz Hayes, 1939: 384). Domingo Faustino Sarmiento pone como epígrafe a Recuerdos de Provincia (1850), además de una cita de Shakespeare, una cita tomada del ensayo "Del ejercicio" (II, VI) de Montaigne: "Decir de sí menos de lo que hay, es necedad y no modestia; tenerse en menos de lo que uno vale es cobardía y pusilanimidad, según Aristóteles" (Montaigne, en Sarmiento, 1850: III). La ilustre lista sigue con el ecuatoriano Juan Montalvo, quien ve en Montaigne a un "educador deleitoso", y con ello inaugura una de las líneas de lectura posibles de Montaigne, maestro de moral y educador:

Y, quién lo creyera, los Ensayos de Montaigne son una de las obras más excelentes y agradables que podemos haber a las manos; de esas obras que nos hacen olvidar comida, sueño, barba, y nos instruyen tanto cuanto nos deleitan. Por eso han dicho que el que ha leído a Plutarco, Séneca y Montaigne puede hacer de cuenta que ha leído cuanto bueno hay que leer en el mundo (1882: 29).

Modernistas como Darío y Rodó se refirieron también a Montaigne. También en la permanente defensa martiana de la naturaleza como criterio de conocimiento y autenticidad es posible descubrir los ecos de Montaigne y Emerson.

En su etapa de madurez, el pensador cubano Enrique José Varona (1849-1933) abandona la confianza positivista de su juventud para llegar a una postura escéptica, y es 
en ese momento cuando la lectura de Montaigne se vuelve fundamental para él (Rojas Osorio, 2002: 34).

Progresivamente, y conforme avance el siglo XX, la presencia y evocación esporádica de la obra de Montaigne y el acento en las cuestiones morales y educativas, irán cediendo su sitio a una mayor preocupación por su postura escéptica, su estilo y los aportes de su pensamiento, que se redescubren a través de Nietzsche y Schopenhauer.

Esta relectura de Montaigne en el siglo XX obedece tanto a una nueva etapa en el ensayo como a que comienzan a circular con mayor facilidad las traducciones de Montaigne y los primeros comentaristas de su obra, y el avance editorial permite que se produzcan en América las primeras grandes antologías y traducciones de los Ensayos. Retomo una importante idea de Marielle Macé, quien plantea que el ensayo debe enfrentar en el siglo XX un desafío singular: mostrar qué tipo de saber es el que proporciona la literatura. El ensayo es también un género reflexivo, un estilo de pensamiento propio de la tradición literaria (2006: 5).

Una vez que entra en crisis el modelo positivista, la literatura y las humanidades redefinen su papel, su lugar, en el concierto del conocimiento, y el ensayo se asociará a la idea de crítica y a la figura del intelectual.

\section{La historia universal de una persona}

Para el escritor argentino Ezequiel Martínez Estrada, Montaigne representa un filósofo y un maestro impremeditado. En su libro Heraldos de la verdad leemos:

El ensayo, tal como lo concebimos hoy, está en Montaigne acabado en punto de perfección. No crea él ese género, pero lo constituye al fijarle sus condiciones típicas, como la forma más holgada y libre de reglas para la expresión natural del pensamiento y la emoción (1958: 7).

Nos ofrece imágenes imborrables de Montaigne y el ensayo, como "historia universal de una persona" (1958: 9) y en el Panorama de las literaturas dice que "sus ensayos son como un viaje de exploración al interior de sí mismo" (1946: 138). Estos elementos que he estudiado en detalle en otro lugar (Weinberg, 2014), y que aquí retomo brevemente, constituyen un temprano y valioso aporte a la teoría del ensayo: entre ellos, su carácter de escritura del yo; su vínculo con la experiencia, con la corporalidad y con la situación vital del autor en el mundo.

La idea del ensayista como crítico que toma distancia de la propia cultura y desenmascara el espíritu dogmático al punto de convertirse en "autoexiliado" nos descubre un rasgo que autores como Edward Said y Pierre Glaudes marcarán como consustanciales al trabajo intelectual y al ensayo. Sus observaciones sobre la "sinceridad" y la "verdad" en la obra de Montaigne son también adelantadas, como lo es su énfasis en la representación vital del yo: "sólo en este sentido se explica que la lectura de sus Ensayos nos dé la impresión física de su presencia y de que, una vez hecho de nuestros autores 
preferidos, sintamos con él los vínculos naturales y misteriosos de la amistad" (1958: 2526). Su énfasis en la vitalidad, el cuerpo, la gestualidad, se aproximan al acercamiento de Starobinski a un Montaigne en movimiento (1968).

Martínez Estrada plantea además interesantes reflexiones en torno al estilo y el ensayo, como lo harán más tarde estudiosos como Juan Marichal (1971) o Pierre Glaudes (1999). Dice también que Montaigne hizo del arte de escribir y de la prosa "un instrumento para siempre capaz de servir al hombre como su idioma materno, como su idioma de gestos, como su persona viviente lanzada al mundo para crecer y multiplicarse en las almas. Pues si escribe como piensa es siempre porque está pensando en escribir" (1958: 90). Hace interesantes apuntes sobre la libertad y la calidad arborescente del ensayo, que conduce a la posibilidad de crecer reticularmente por coordinación y adición tanto como por subordinación y jerarquización de las ideas: se trata de una observación que hoy es fundamental en estudios sobre el género (Bensmaïa, 1987; Ferrecchia, 2000). Interesante es también su capacidad de observar la relación entre el autor y su obra a través del libro, ya que "Montaigne hizo del ensayo su imagen literaria fiel" (1958: 9). Observa además el carácter proteico del género: "Como él, es un ser proteico, amorfo, susceptible de transformarse hasta adquirir un cuerpo vivo, una cara, una voz. Su estilo es igual a su pensamiento" (1958: 9).

Todo ensayista lee desde la propia perspectiva, la hace ostensible, la inscribe en una tradición, encuentra una genealogía para la propia obra, y en este sentido nuestro autor lee a Montaigne y lee desde Montaigne. Al considerar los ensayos como una "apropiación" de las lecturas, vuelve a representar, a dramatizar, el performance originario de su maestro: "y hasta se ha querido percibir en su movimiento el andar del autor por su biblioteca" (1958: 74); "tal como era Montaigne viviendo, tal era escribiendo" (1958: 75). Estas observaciones apuntan a la relación entre la escritura y la biblioteca, la escritura y la lectura, la escritura y la vida. Cada ensayista funda su propia biblioteca simbólica a partir de los libros de los otros. Todo ensayista pinta su tema desde su propia situación, de modo tal que el punto de vista singular actúa como punto de partida del propio texto.

La mirada que dedica a Montaigne traduce sus preocupaciones singulares y de época. Tal es su interés por la defensa de la libertad del individuo pensante contra las restricciones de las instituciones; la educación en la libertad contra la pedagogía escolar y el dogmatismo; la tolerancia contra el fanatismo; la sinceridad y la responsabilidad como principios constructivos del ensayo. Por su originalidad, penetración e interés las reflexiones de Martínez Estrada, seguidor además de Nietzsche, configuran un capítulo valioso de los estudios montaigneanos. 
Montaigne y el ensayo del Nuevo Mundo

\section{Las dimensiones de la imaginación}

La figura misma del autor de los Ensayos ha recibido también un tratamiento literario notable por parte de nuestros escritores: pensemos en Un seguidor de Montaigne mira La Habana, del cubano Antonio José Ponte (1995), que nos coloca en un lugar textual en que se cruzan ensayo, crónica y autobiografía, o en La muerte de Montaigne, novela del chileno Jorge Edwards (2011) que constituye un complejo tejido de ensayo, ficción, meditación, puesta en diálogo con un autor que lo acompañó a lo largo de su vida.

Para terminar, y para atenernos al tan productivo periodo en que se centra nuestro trabajo, recordaremos a otros dos grandes escritores que se acercaron a Montaigne desde la literatura y fueron pioneros en la apertura de esta posibilidad de recreación estética de su figura, en la clave de las Vidas imaginarias de Marcel Schwob, quien decía, en el prefacio a esta obra, que el escritor no debe actuar como historiador sino como retratista, como artista, y plantea también que "los biógrafos, por desgracia, han creído, generalmente, que eran historiadores y así nos han privado de retratos admirables" (Schwob, 1980: 14). Dice también que si a la historia le interesa generalizar, al arte le interesa particularizar, hacer de los detalles secundarios un foco de atracción estética. Borges y Arreola nos ofrecerán dos posibilidades de ese "retrato imaginario" de Montaigne.

Así, el schopenhaueriano Borges dedicó unas páginas notables a Montaigne en una plaquette publicada en 1957 por la casa editora Colombo de Buenos Aires, que lleva por título "Montaigne, Walt Whitman”. Allí leemos:

La más tranquila de las revoluciones francesas tal vez ocurrió así:

Michel Eyquem, señor de Montaigne, leía (releía) en su biblioteca las obras menores de Plutarco, vertidas al francés por Amyot. Sabemos que la biblioteca era circular y que abarcaba el segundo piso de una torre $[\ldots]$ le gustaba leer y seguir leyendo esas cosas no interesantes. [Y aquí el giro borgeano:] Estas cosas me agradan, reflexionó, porque las escribe Plutarco, porque las pronuncia la voz. llamada Plutarco. Montaigne había comprendido que el griego no era sólo un maestro y una doctrina, sino una entonación individual a la que se había acostumbrado, un hombre y su diálogo.

Desde aquel instante en que percibió que entre alguien y un libro puede existir una relación de amistad, Montaigne ya era el autor de la obra entrañable. Lo demás está en las enciclopedias. En 1580 aparecieron los Essais, el primer libro que deliberadamente busca lo que Plutarco halló en otro país, mediante otra lengua, al cabo de siglos de muerte: el afecto de un hombre desconocido. Los ensayos que abren el volumen son impersonales; también es lícito conjeturar que Montaigne se había propuesto compilar una miscelánea, una silva de varia lección, al gusto de la época, y que, releyendo sus borradores, reconoció en ellos su voz, el sonido de su alma, y decidió incorporarlos en una obra que fuera su verídica imagen. 
Seguir la descendencia de la obra, la multiplicación de su linaje por toda Europa, sería reescribir la historia de la literatura [...]

Montaigne había prevenido al lector para que éste no se llamara a engaño: Je suis moy-mesme la matière de mon livre [...] (2003: 37-38).

Otro autor que nos aporta una visión literaria de Montaigne es Juan José Arreola, quien escribe: "Hay un linaje de espíritus que no pueden irse de este mundo sin dejar un testimonio escrito. Son los encargados de denunciar al hombre frente al hombre mismo, para revelarle otra vez su grandeza y su miseria. Tal parece que en ellos la experiencia humana se deposita en una sola conciencia desmesurada y lúcida" (1995: 687).

En este retrato, el interés por completar desde la imaginación la vida real de un personaje marginal o poco conocido, de modo tal que los detalles secundarios o incompletos de esa vida actúen como disparadores para el trabajo artístico del propio autor, nos conduce a otra forma de tratamiento por parte de Arreola, que para el caso de Montaigne implica abrir una veta genial de comprensión de la mise en abyme que significa el juego entre retrato y ensayo. De este modo, la operación imaginaria a la que Arreola somete a Montaigne, retratado como persona e ideado como personaje, nos permite asomarnos a uno de los grandes enigmas de Montaigne y los ensayos, y "da en el clavo", por decirlo así, "en cuanto Montaigne es por fuerza autor de un solo libro. Parece inconcebible que hubiera escrito otras obras aparte de sus Ensayos. Su libro es siempre, necesariamente, el mismo, porque en el fondo aspira a ser él mismo, Montaigne pretende identificarse plenamente con su obra" (Navarro Reyes, 2003: 271).

Arreola desemboca, por sus antípodas, en uno de los enigmas más grandes que nos depararon los ensayos de Montaigne: ¿cómo se relaciona el uno con el todo?, ¿cómo tratar lo singular, lo particular, lo único? ¿Y cuál es nuestro papel como lectores de esa vida? ¿Podemos entenderla a cabalidad, podemos entender aunque más no sea a cabalidad un instante de una vida ajena? ¿Estamos fatalmente condenados a no comprender la experiencia del otro? ¿O estamos fatalmente condenados a recrearla apelando a elementos de la imaginación y la ficción? ¿Qué relación hay entre el texto propio y el texto ajeno, cuando "el texto propio, realizado como pura manifestación de la interioridad, logra ponerse en pie gracias al apoyo de los textos ajenos" (Navarro Reyes, 2003: 272)? Al seleccionar, estilizar, reagrupar, reinterpretar las circunstancias históricas de la vida de Montaigne, una vida realmente vivida, Arreola la relee con las claves de una vida imaginaria y recrea los rasgos y gestos de un autor de carne y hueso.

Cierro mi artículo con una cita de Arreola:

De las páginas de los Ensayos brota una lección de concordia universal, apoyada en la tolerancia. Enemigo de toda coacción moral y de cualquier forma de represión violenta, Montaigne aparece en su siglo cada vez más solitario y más grande, inaugurando el ejercicio de un ideal que sigue siendo nuestro porque no hemos acabado de convertirlo en realidad: el de la convivencia pacífica. Mirando más 
allá de sus fronteras nacionales, reconoció como prójimos a todos los hombres [...] (1995: 689).

De este modo, y por paradójico que parezca, las operaciones imaginarias de Borges y Arreola nos conducen, por sus antípodas, a algunas de las derivas más inesperadas y ricas del retrato de Montaigne, quien hizo a través de la escritura un complejo sistema de espejos. Estos grandes de la literatura latinoamericana nos llevan a asomarnos, mediante las operaciones de la imaginación, a uno de los puntos más altos, complejos y abismales de los ensayos, donde la especulación filosófica se toca con la creación literaria, donde el retrato de una vida individual se toca con la condición humana.

\section{Referencias bibliográficas}

Arciniegas, Germán (1979) [1963]. Nuestra América es un ensayo. Latinoamérica. Cuadernos de cultura Latinoamericana, 53.

Arreola, Juan José (1995) [1959]. Prólogo [a los Ensayos escogidos, de Montaigne]. En: Yurkievich, Saúl (antol. y pról.). Obras. México: FCE. 679-690.

Bensmaia, Réda (1987). The Barthes Effect: The Essay as Reflective Text. Minneapolis: University of Minnesota Press.

Borges, Jorge Luis (2003) [1957]. Montaigne, Walt Whitman. En: Textos recobrados 19561986. Buenos Aires: Emecé. 37-40.

Darío, Rubén (1907) [1905]. En la muerte de Rafael Núñez. En: Cantos de vida y esperanza. Los cisnes y otros poemas. Barcelona: F. Granada y Compañía. 63-64.

Desan, Philippe (2007) [2004]. Dictionnaire de Michel de Montaigne. París: Honoré Champion. Edwards, Jorge (2011). La muerte de Montaigne. Barcelona: Tusquets.

Ferrecchia, Maria (2000). Il saggio come forma letteraria. Lecce: Pensa Multimedia.

Glaudes, Pierre-Louette, Jean-François (1999). L'Essai. Paris: Hachette.

Henríquez Ureña, Pedro (1949) [1945]. Las corrientes literarias en la América Hispánica. Traducción de Joaquín Díez-Canedo. México: FCE.

Macé, Marielle (2006). Le temps de l'essai. Histoire d'un genre en France au XX'e siècle. París: Belin. Marichal, Juan (1971). La voluntad de estilo. Teoría e historia del ensayismo hispánico. Madrid: Selecta de Revista de Occidente.

Martínez Estrada, Ezequiel (1958). Heraldos de la verdad: Montaigne, Balzac, Nietzsche. Buenos Aires: Nova.

Martínez Estrada, Ezequiel, (1946). Panorama de las literaturas. Buenos Aires: Claridad.

Montaigne, Michel de (1998) [1580-1595]. Ensayos. Traducción y edición de Dolores Picazo y Almudena Montojo. 3 vols. Madrid: Cátedra. 
Montaigne, Michel de (1962). Oeuvres complètes. Edición de Albert Thibaudet y Maurice Rat. París: Gallimard.

Montalvo, Juan (1882). "Del genio”. En: Siete tratados, tomo II. Besanzón: Imprenta de José Jacquin. 5-72.

Navarro Reyes, Jesús (2003). Lo propio y lo ajeno: génesis de los Ensayos de Montaigne. Cuadernos sobre Vico, 15-16. 271-290.

Ponte, Antonio José (2014) [1995]. Un seguidor de Montaigne mira La Habana. Buenos Aires: Corregidor.

Reyes, Alfonso (1960) [1920-1941]. El presagio de América. En: Obras Completas, tomo XI. México: FCE. 11-62.

Rodó, José Enrique (1993) [1909]. Ariel. Motivos de Proteo. Caracas: Biblioteca Ayacucho.

Rojas Osorio, Carlos (2002). Latinoamérica: cien años de filosofía. San Juan de Puerto Rico: Isla Negra.

Sáenz Hayes, Ricardo (1939). Miguel de Montaigne (1533-1592). Buenos Aires: Espasa-Calpe. Said, Edward (1983). The World, the Text and the Critic. Cambridge: Harvard University Press. Sarmiento, Domingo Faustino (1850). Recuerdos de provincia. Santiago [de Chile]: Imprenta de Julio Belin y Compañía.

Schwob, Marcel (1980) [1896]. Vidas imaginarias. Traducción de Julio Pérez Millán. Buenos Aires: Centro Editor de América Latina.

Starobinski, Jean (1968). Montaigne en mouvement. París: Gallimard.

Weinberg, Liliana (2014). El ensayo en busca del sentido. México-Madrid-Berlín: CIALC, UNAM-Iberoamericana-Vervuert. 